University of New Mexico

UNM Digital Repository

$1-1-1989$

\title{
Sex change and population fluctuations in Pandalid Shrimp
}

Paul Anderson

Eric Charnov

Follow this and additional works at: https://digitalrepository.unm.edu/biol_fsp

Part of the Biology Commons

\section{Recommended Citation}

American Naturalist 134:824-827

This Article is brought to you for free and open access by the Academic Department Resources at UNM Digital Repository. It has been accepted for inclusion in Biology Faculty \& Staff Publications by an authorized administrator of UNM Digital Repository. For more information, please contact disc@unm.edu. 


\section{SEX CHANGE AND POPULATION FLUCTUATIONS IN PANDALID SHRIMP}

Sex-allocation theory applied to sex reversal generally predicts that the age and/or size at sex reversal should show variation linked to the underlying age and/or size distribution of the breeding population (Leigh et al. 1976; Charnov et al. 1978; Hoagland 1978; Charnov 1979, 1982). Spatial or temporal variation in the age and/or size distribution of breeding adults may result from any of a number of factors: biogeographic (large-scale, between-population) variation in growth and/or mortality; small-scale variation in growth, mortality, or social-group structure; or year-to-year variation in growth, mortality, or recruitment (e.g., Albers and Anderson 1985). All these forms of variation have been used to look at adaptive sex change and to review much of the current fish and invertebrate work (Charnov 1979, 1982). Of particular interest is the small-scale variation in sex change, a form of phenotypic plasticity whereby an individual alters its age and/or size at sex change to match current breeding opportunities. Sex-reversing organisms that live in stable social groups are known to show labile sex change, whereby an individual alters the time or size at which it changes sex according to the sex and size identity of its immediate neighbors (Charnov 1982; Shapiro 1987). Such labile sexuality is widespread in coral-reef fish (Fishelson 1970; Robertson 1972; Fricke and Fricke 1977; Warner 1984, 1988; Shapiro 1987) and invertebrates such as the limpet Crepidula (Hoagland 1978) and the polychaete Ophryotrocha (Bacci 1965).

Protandrous pandalid shrimp do not live in stable social groups; yet there is strong correlational evidence that individuals alter their age and/or size at sex change in the face of year-to-year fluctuations in population age $(=$ size $)$ structure (Charnov et al. 1978), caused mainly (but not entirely) by a variation in recruitment from the planktonic larval phase (Albers and Anderson 1985). This earlier evidence is for Pandalus jordani off the west coast of North America. At the study locations, the shrimp is short-lived (only two breeding age groups), and the age structure fluctuates greatly from year to year. This work plus several other forms of evidence strongly argued that pandalid shrimp, at a single location, have neither a fixed size nor a fixed age at sex change and that the age or size at sex change alters in response to year-to-year variation in the age and/or size distribution of breeding adults (review in Charnov 1982). In years when most of the breeders are larger, so is the size at sex change (Charnov et al. 1978).

We present here further correlational evidence in support of the notion that year-to-year fluctuations in the population size distribution are tracked by yearto-year variation in the size at sex change. Our data complement earlier work

Am. Nat. 1989. Vol. 134, pp. 824-827.

(c) 1989 by The University of Chicago. 0003-0147/89/3405-0013\$02.00. All rights reserved. 
TABLE 1

Number of Shrimp $(N)$, Calculated Mean Size

$(\bar{x})$, AND OBSERVED Srze $\left(x_{0.5}\right)$

\begin{tabular}{lrcl}
\hline $\begin{array}{c}\text { Survey } \\
\text { Year }\end{array}$ & $N$ & $\bar{x}$ & $x_{0.5}{ }^{*}$ \\
\hline 1972 & 2243 & 17.00 & 19.75 \\
1973 & 186 & 16.56 & 19.25 \\
1974 & 1905 & 17.43 & 18.75 \\
1975 & 2721 & 17.53 & 19.00 \\
1976 & 2424 & 17.23 & 19.50 \\
1977 & 3471 & 19.20 & 19.50 \\
1978 & 5363 & 18.59 & 20.00 \\
1979 & 2439 & 15.59 & 18.25 \\
1980 & 2654 & 16.45 & 17.00 \\
1981 & 2553 & 18.10 & 19.75 \\
1982 & 4636 & 17.02 & 17.50 \\
1983 & 4063 & 16.11 & 16.75 \\
1984 & 3381 & 17.06 & 15.50 \\
1985 & 5523 & 15.10 & 16.75 \\
1986 & 8600 & 15.38 & 15.50 \\
1987 & 3320 & 17.35 & 17.75 \\
\hline
\end{tabular}

Note.-Data are for Pandalus borealis from Pavlof Bay, 1972-1987. Sizes in millimeters.

* Size at which $50 \%$ of the shrimp were identified as female.

(Charnov et al. 1978) in that the shrimp in our study, Pandalus borealis, is relatively long-lived at the study location, having a life span more than double that of the California species. Indeed, here we provide the analysis in terms of size, rather than age, because separate age groups cannot easily be recognized.

Pavlof Bay, on the southern side of the Alaska Peninsula, supported one of the world's largest pandalid shrimp fisheries until 1979, and about $70 \%$ of the catches consisted of the northern shrimp, Pandalus borealis (Anderson 1981, MS). Although the area was closed to fishing after the catches abruptly declined in the late 1970s, a scientific sampling program has been carried out by the U.S. government since 1972. Data collected from these surveys include carapace-length frequencies by sex and estimates of abundance during the late summer-fall breeding season. The shrimp breed only once a year and at this location have a life span of 8-10 yr; sex change takes place sometime between the third and sixth year of life. Sampling methods are detailed elsewhere (Anderson 1981). In all, the data span $16 \mathrm{yr}$, 1972 through 1987.

In order to ask whether the size at sex change altered from year to year, in concert with the prevailing population size distribution that year, we performed the following correlation analysis. The size at sex change was defined as the size at which $50 \%$ of the individuals were female $\left(x_{0.5}\right)$. To summarize the position of the population size distribution, we simply used the average size of a breeding individual $(\bar{x})$. This measure for the position of the population size distribution is biased since the sampling gear underestimates the number of small shrimp; larger shrimp are much more vulnerable to the gear (Charnov et al. 1978; Anderson 1981, 


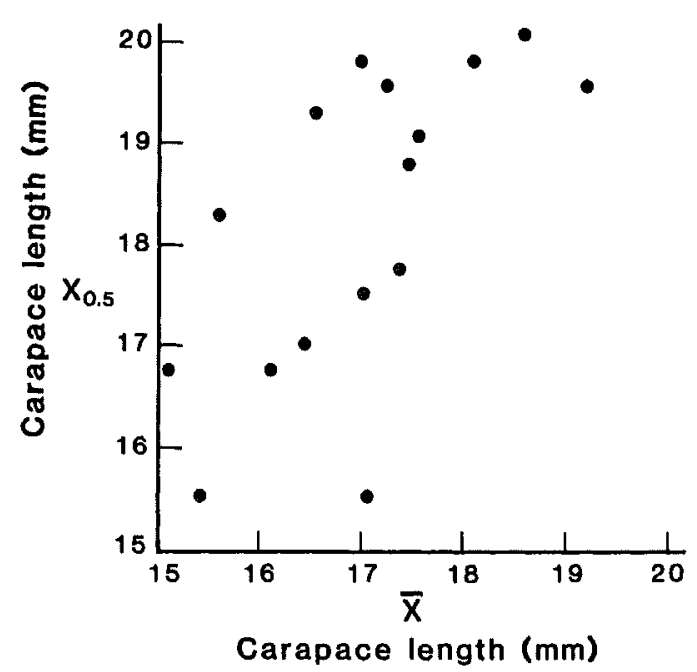

FIG. 1.-The size at which $50 \%$ of the individuals are female $\left(x_{0.5}\right)$ correlates positively with the position of the overall size distribution of the breeding population, as indexed simply by the mean size of a breeder, $\bar{x}(r=0.65, P<0.01)$.

MS). However, we have no reason to believe that the bias alters from year to year in any consistent fashion. Table 1 summarizes the data; in all, about 55,000 shrimp were sampled over the 16 -yr period. Figure 1 shows the plot of $x_{0.5}$ versus $\bar{x}$. The correlation is significant at the $1 \%$ level. We believe that the relation demonstrated here (fig. 1) suggests that the size at sex change tracks the population size distribution. Sampling limitations preclude a stronger statement, and pandalid shrimp are poor candidates for experimental manipulation.

\section{LITERATURE CITED}

Albers, W. D., and P. J. Anderson. 1985. Diet of Pacific cod, Gadus macrocephalus, and predation on the northern pink shrimp, Pandalus borealis, in Pavlof Bay, Alaska. U.S. Natl. Mar. Fish. Fish. Bull. 83:601-610.

Anderson, P. J. 1981. A technique for estimating growth and total mortality for a population of pink shrimp Pandalus borealis from the western Gulf of Alaska. Pages 331-342 in T. Frady, ed. Proceedings of the International Pandalid Shrimp Symposium, Kodiak, Alaska, February 1315, 1979. Sea Grant Program, Sea Grant Rep. 81-3. University of Alaska, Fairbanks.

Bacci, G. 1965. Sex determination. Pergamon, Elmsford, N.Y.

Charnov, E. L. 1979. Natural selection and sex change in pandalid shrimp: test of a life history theory. Am. Nat. 113:715-734.

1982. The theory of sex allocation. Princeton University Press, Princeton, N.J.

Charnov, E. L., D. Gotshall, and J. Robinson. 1978. Sex ratio: adaptive response to population fluctuations in pandalid shrimp. Science (Wash., D.C.) 200:204-206.

Fishelson, L. 1970. Protogynous sex reversal in the fish Anthias squamipinnis regulated by the presence or absence of a male fish. Nature (Lond.) 227:90-91.

Fricke, H. W., and S. Fricke. 1977. Monogamy and sex change by aggressive dominance in coral reef fish. Nature (Lond.) 266:830-832.

Hoagland, K. E. 1978. Protandry and the evolution of environmentally mediated sex change: a study of the Mollusca. Malacologia 17:365-391. 
Leigh, E. G., E. L. Charnov, and R. R. Warner. 1976. Sex ratio, sex change and natural selection. Proc. Natl. Acad. Sci. USA 73:3655-3660.

Robertson, D. R. 1972. Social control of sex reversal in a coral-reef fish. Science (Wash., D.C.) 177:1007-1009.

Shapiro, D. Y. 1987. Sexual differentiation, social behavior and the evolution of sex change in coral reef fishes. BioScience 37:490-497.

Warner, R. R. 1984. Mating behavior and hermaphroditism in coral reef fishes. Am. Sci. 72:128-136. . 1988. Sex change in fishes: hypotheses, evidence and objections. Environ. Biol. Fishes 22: 81-90.

\section{Department of Biology}

Eric L. Charnov

UNIVERSITY OF UTAH

Salt Lake City, Utah 84II2

National Marine Fisheries Service

Paul J. Anderson

U.S. Department of Commerce

Northwest and Alaska Fisheries Center

P.O. Box 1638

Kodiak, Alaska 996I5

Submitted July 14, 1988; Accepted December 11, 1988 